\title{
Social dimensions related to anaemia among women of childbearing age from rural India
}

\author{
Shobha Rao*, Smita Joshi, Pradnya Bhide, Bhairavi Puranik and Asawari Kanade \\ Biometry and Nutrition Department, Agharkar Research Institute, G.G. Agarkar Road, Pune - 41 1004, \\ Maharashtra, India
}

Submitted 25 January 2010: Accepted 27 August 2010: First published online 13 October 2010

\begin{abstract}
Objective: To examine various sociodemographic aspects related to consumption of micronutrient-rich foods like green leafy vegetables (GLV), which will be helpful in modifying dietary habits, a strategy that merits consideration for prevention of anaemia.

Design: Cross-sectional study for collecting data on socio-economic and anthropometric (weight, height) variables, Hb, dietary pattern (FFQ) and peripheral smear examination for classifying nutritional and iron-deficiency anaemia (IDA). Setting: Three villages near Pune city, Maharashtra, India.

Subjects: Rural women ( $n$ 418) of childbearing age (15-35 years).

Results: Mean Hb was 11.07 g/dl. Seventy-seven per cent of the women were anaemic $(\mathrm{Hb}<12 \mathrm{~g} / \mathrm{dl})$ and $28 \%$ had IDA, indicating that a large proportion of the women had nutritional anaemia. Higher prevalence of IDA was associated with several sociodemographic and maternal parameters, but multiple logistic regression analysis showed significant $(P<0.05)$ risk of IDA with lower body weight $(<40 \mathrm{~kg})$, short maternal height $(<145 \mathrm{~cm})$, younger age at marriage $(<19$ years) and higher parity $(\geq 2)$. Various socio-cultural reasons associated with low consumption of GLV included non-cultivation of GLV, priority for selling them rather than home consumption, dislike of GLV by husband and children, and lack of awareness about different recipes for GLV.

Conclusions: Our findings highlight that low consumption of GLV, which are treasures of micronutrients including $\mathrm{Fe}$, is associated with genuine social reasons. This indicates a need for developing action programmes to improve nutritional knowledge and awareness leading to enhanced consumption of Fe-rich foods for preventing anaemia in rural India.
\end{abstract}

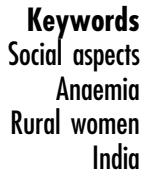

Keywords Anaemia India
Micronutrient deficiencies continue to impose a substantial health, economic and social burden worldwide. Fe deficiency continues to be the leading single nutrient deficiency in the world, affecting more than two billion persons despite considerable efforts to decrease its prevalence for the past three decades ${ }^{(1)}$. Nutritional anaemia remains a major public health problem in nearly all developing countries, including India. Its prevalence in pregnant women has been reported to be in the range of 33 to $89 \%$ in different studies ${ }^{(2-8)}$ reported from India and continues to be a major factor responsible for infant prematurity and low birth weight. The nutritional handicap thus accumulated in the life of women is passed on to the next generation through low birth weight. Therefore there is a growing realization that specific programmes for addressing the nutritional and health requirements of women of childbearing age are a key strategy for reaching population health targets.
Although the National Nutritional Anaemia Prophylaxis Programme has been in operation since 1970, under which $\mathrm{Fe}$-folic acid tablets are distributed to pregnant women, the evaluation of the programme conducted during 1985-1986 showed no impact on the prevalence of anaemia ${ }^{(4)}$. In fact, prevalence rates were essentially the same as those reported in earlier studies $^{(9,10)}$ carried out during the 1940s, 1950s and 1960s. In practice, the efficiency of large-scale programmes has been limited for various reasons such as poor access to prenatal care, insufficient and inconsistent supply of Fe supplements, insufficient counselling on the need for and the benefits of Fe supplements and an unwillingness by pregnant women to take Fe supplements ${ }^{(11)}$. Besides, malarial infections and worm infestations, factors known to be associated with anaemia, are commonly prevalent in rural areas. Thus larger the prevalence of anaemia, the more likely it is to have multiple causes and not 
be related solely to Fe deficiency. Nevertheless, the importance of dietary deficiencies cannot be overlooked as iron-deficiency anaemia (IDA) resulting from inadequate intake and low absorption of dietary Fe has been shown to be the most common cause of anaemia in India $^{(12,13)}$.

Several developing countries seem to be in the process of increasing either the dose of elemental Fe (from $60 \mathrm{mg}$ to $100 \mathrm{mg}$ daily) as has been done in India or changing the frequency of supplementation. However this is unlikely to bring beneficial effects for reducing anaemia because, in many populations and especially those with limited access to animal foods rich in haem $\mathrm{Fe}$, Fe deficiency is likely to be compounded by multiple micronutrient deficiencies. Reported data show not only that the dietary intakes of rural Indian mothers are low in energy and protein $^{(14-17)}$, but also that their consumption of foods that are important sources of micronutrients, such as green leafy vegetables (GLV), fruits, milk and meat, is extremely low ${ }^{(18)}$. It follows that, in addition to supplementation programmes of $\mathrm{Fe}-$ folic acid tablets, simultaneous efforts for increasing the consumption of micronutrient-rich vegetarian foods are also essential. Clearly, GLV form the food group of potential interest as they are a rich and cheap source of all vitamins and minerals and are easily available compared with fruits and milk. In view of the fact that food provides a combination of micronutrients unlike the single nutrient provided by a tablet, more research is urgently needed for understanding the reasons for low intakes of such foods, especially GLV, in rural India. The present study attempted to examine various aspects, including socio-cultural and demographic, related to food consumption patterns with a view to identifying programmes that will help modify dietary habits, a strategy that merits consideration for prevention of anaemia.

\section{Materials and methods}

\section{Participants}

Three villages (Dhamari, Hivare and Pimple) situated within $45 \mathrm{~km}$ of Pune district, Maharashtra, India were considered for the study. The villages represented typical Indian villages and were largely homogeneous. In this cross-sectional study, a census was done of all houses in these villages to get a list of eligible women from each house. The census covered a total population of 8300 individuals and the initial number of eligible (age 15-35 years) non-pregnant women was 418. Most women were from the subsistence farming community and were residing in an extended family with their in-laws. Women were enrolled in the study only after their oral consent.

\section{Preliminary information}

Each woman enrolled in the study was interviewed by a nutritionist in a home visit, during which a field-tested structured questionnaire was administered to obtain personal information, obstetric history and a dietary assessment. Personal information comprised the woman's current age, age at menarche, age at marriage, education, type of income-generating work and whether engaged in any work other than household work. For obstetric history the woman was interviewed for information on parity, outcome of previous deliveries, place of delivery and birth weight of offspring if known; also the practice of giving colostrum etc. was recorded. An FFQ developed in an earlier study ${ }^{(19)}$ for rural mothers from villages in the same area was used for assessing the habitual dietary patterns. Nevertheless, the FFQ was field-tested before use in the present study but no changes were required. After the interview was over, women were measured for weight (within $200 \mathrm{~g}$ accuracy) using a portable digitaldisplay weighing balance (Atco Corporation Ltd, Delhi, India) and height was measured (within $0 \cdot 1 \mathrm{~cm}$ accuracy) using a stadiometer (Galaxi Informatics, Delhi, India).

\section{Informal meetings}

Informal group meetings were conducted at a common place (a room of kindergarten school) in each village, once a month, with a nutritionist and a lady doctor. A wide range of issues related to pregnancy, such as increased requirements in pregnancy, importance of macro- and micronutrients in relation to birth size and anaemia, various possible complications in pregnancy, importance of giving colostrum, appropriate breast-feeding and weaning practices, and symptoms and adverse effects of anaemia, were discussed in the local dialect.

\section{Hb estimation}

A trained technician accompanying the research team drew a venous blood sample $(2 \mathrm{ml})$ from each woman into an EDTA tube. The tubes were transported to a pathology laboratory in Pune, taking proper precautions. The samples were immediately analysed for $\mathrm{Hb}$ by the cyanmethaemoglobin method and a peripheral smear examination (i.e. colour, size and shape of red blood cells (RBC)) was conducted. The blood smear was prepared, stained with Leishman stain and covered for $2 \mathrm{~min}$; then alkaline buffer solution was added. After 10 min the smear was washed with running distilled water, dried and observed under a microscope to classify nutritional and Fe-deficiency anaemia ${ }^{(20)}$. Normocytic normochromic cells were considered as normal, while normocytic hypochromic with the presence of macrocytic cells were considered as nutritional anaemia indicative of probable vitamin deficiency. Additionally, hypochromic normocytic cells with anisocytosis were also considered as nutritional anaemia. Only hypochromic microcytic cells with anisocytosis/poikilocytosis were considered indicative 
of IDA. The peripheral smear was also examined for the presence of malarial parasites.

\section{Structured interviews}

Besides administering the FFQ, the nutritionist also conducted a detailed interview with each woman using a structured questionnaire for obtaining information on socio-cultural aspects related to consumption of GLV. For example, the questionnaire contained questions on how often GLV are consumed rather than sold; how often GLV are cooked; if not, reasons for not cooking; methods of cooking; types of recipe made from GLV; who decides what to cook; how often GLV are purchased from the market; the reasons for not purchasing; interest of the rural mother in kitchen garden activities; and use of disposed water from the kitchen for growing plants.

\section{Composition of the research team and their roles}

The research team comprising a lady doctor, two nutritionists and a technician visited each study village once per fortnight. The role of the lady doctor was to conduct informal meetings for imparting health-related information while the nutritionist talked about nutrition-related issues and the technician was responsible for collecting the women's blood samples. Nutritionists were often helpful in explaining to the women the importance of checking blood and to clear any doubts that women had. The nutritionists also provided initial and recurrent training to community health workers (CHW) for keeping records of social activities.

\section{Community bealth workers}

Young married girls from the local community, who had schooling up to 10th standard and good rapport with the rural women, were appointed for each village to act as mediators between the research team and the study participants. Since most women were engaged in farming it was necessary to motivate them for attending the meetings. Similarly, many women had a fear of giving blood samples. Therefore, the role of $\mathrm{CHW}$ was to motivate women for attending meetings and for giving blood samples through effective communication, for which they were trained. Their duties thus involved visiting each women a couple of times to inform about the date and time of meetings, keeping the attendance record of the meetings, distributing the blood report and occasionally accompanying the technician for collecting the blood sample of women not attending the meetings.

\section{Statistical methods}

Differences and linearity in mean $\mathrm{Hb}$ values for different groups of women were tested using one-way ANOVA. The proportions of women with IDA in various categories of anthropometric measurements were tested for trend using the $Z$ test $^{(21)}$. Multiple logistic regression analysis was carried out for computing odds ratios for risk of IDA
Table 1 Sociodemographic characteristics* of the study participants: rural women of childbearing age (15-35 years), Maharashtra, India

\begin{tabular}{lrc}
\hline Variable & $n$ & Frequency (\%) \\
\hline Age at menarche (years) & & \\
$\quad<14$ & 93 & $23 \cdot 1$ \\
$14-15$ & 144 & $35 \cdot 7$ \\
$15-16$ & 98 & $24 \cdot 3$ \\
$\geq 16$ & 68 & $16 \cdot 9$ \\
Age at marriage (years) & & \\
$\quad<16$ & 57 & $14 \cdot 2$ \\
$16-18$ & 148 & $36 \cdot 9$ \\
$18-20$ & 123 & $30 \cdot 7$ \\
$\geq 20$ & 73 & $18 \cdot 2$ \\
Education & & \\
$\quad<4$ th standard & 48 & $11 \cdot 8$ \\
5th-10th standard & 279 & $68 \cdot 6$ \\
$\quad \geq 10$ th standard & 90 & $20 \cdot 0$ \\
Occupation & & \\
$\quad$ Housewife & 135 & $33 \cdot 2$ \\
Farmer or labourer & 255 & $62 \cdot 7$ \\
$\quad$ Other & 17 & $4 \cdot 2$ \\
Obstetric history & & \\
Abortions/stillbirth & 16 & $6 \cdot 7$ \\
Preterm & 15 & $6 \cdot 8$ \\
Full term & 207 & $93 \cdot 2$ \\
\hline
\end{tabular}

*For some women, information on some of the variables was not available.

associated with various factors. All analyses were carried out using the SPSS/PC+ for Windows statistical software package version $11 \cdot 0$ (SPSS Inc., Chicago, IL, USA). Ethical permission was obtained from the Ethical Committee of Agharkar Research Institute before implementing the project.

\section{Results}

\section{Sociodemographic characteristics}

The sociodemographic characteristics of the enrolled women (Table 1) showed that about $12 \%$ had no or low levels of education and only $20 \%$ had schooling above 10 th standard. They were mostly engaged in farming as labourers $(63 \%)$. About $50 \%$ of the women had age at marriage below 18 years, which is the legal age for marriage. Their recalled median age at menarche was between 14 and 15 years, indicating delayed menarche. The retrospective data on their previous deliveries showed a high percentage of pregnancy wastage $(6 \cdot 7 \%)$ and preterm deliveries $(6 \cdot 8 \%)$ with a very high proportion (31.7\%) of low-birth-weight babies. Even today, almost $24 \%$ of deliveries in rural areas take place at home.

\section{Prevalence of anaemia and related factors}

The mean $\mathrm{Hb}$ of these women was $11.07 \mathrm{~g} / \mathrm{dl}$. Only $23 \%$ had $\mathrm{Hb}$ above the normal cut-off $(\mathrm{Hb} \geq 12 \mathrm{~g} / \mathrm{dl}$ ) while $77 \%$ were suffering from some degree of anaemia: $59 \%$ of the women were suffering from mild anaemia $(\mathrm{Hb}=$ $10-12 \mathrm{~g} / \mathrm{dl}), 16 \%$ were suffering from moderate anaemia $(\mathrm{Hb}=8-10 \mathrm{~g} / \mathrm{dl})$ and only $2 \cdot 2 \%$ were suffering from 
Table 2 Classification according to $\mathrm{Hb}$ level and red blood cell morphology: rural women of childbearing age (15-35 years), Maharashtra, India

\begin{tabular}{|c|c|c|c|c|c|c|c|c|}
\hline \multirow[b]{2}{*}{$\mathrm{Hb}(\mathrm{g} / \mathrm{dl})$} & \multicolumn{2}{|c|}{ Normal } & \multicolumn{2}{|c|}{ Nutritional anaemia* } & \multicolumn{2}{|c|}{ Fe-deficiency anaemiat } & \multicolumn{2}{|c|}{ Total } \\
\hline & $n$ & $\%$ & $n$ & $\%$ & $n$ & $\%$ & $n$ & $\%$ \\
\hline$<10$ & - & - & - & - & 75 & $100 \cdot 0$ & 75 & $18 \cdot 2$ \\
\hline $10-11$ & - & - & 43 & $52 \cdot 4$ & 39 & $47 \cdot 6$ & 82 & $19 \cdot 9$ \\
\hline $11-12$ & 74 & $46 \cdot 0$ & 87 & 54.0 & - & - & 161 & $39 \cdot 1$ \\
\hline$\geq 12$ & 94 & $100 \cdot 0$ & - & - & - & - & 94 & $22 \cdot 8$ \\
\hline Total & 168 & $40 \cdot 8$ & 130 & $31 \cdot 6$ & 114 & $27 \cdot 6$ & 412 & 100.0 \\
\hline
\end{tabular}

*Hypochromic cells.

tAnisocytosis and microcytes.

severe anaemia $(\mathrm{Hb}<8 \mathrm{~g} / \mathrm{dl})$. The distribution of $\mathrm{Hb}$ was not skewed.

None of the peripheral smear examinations indicated the presence of malarial parasites. Further, the classification of women by their $\mathrm{Hb}$ level and RBC morphology (Table 2) showed that all women having $\mathrm{Hb}$ below $10 \mathrm{~g} / \mathrm{dl}$ had microcytes and anisocytosis, indicating IDA. In the next category, i.e. $\mathrm{Hb}$ between 10 and $11 \mathrm{~g} / \mathrm{dl}$, none of the blood samples had normal cells and only half (47.6\%) seemed to have IDA while the remaining half indicated nutritional anaemia. However, when $\mathrm{Hb}$ was above $11 \mathrm{~g} / \mathrm{dl}$, almost half of the samples $(46.0 \%)$ had normal cells while the remaining half showed nutritional anaemia, i.e. short-term iron inadequacy. Finally, when $\mathrm{Hb}$ was $\geq 12 \mathrm{~g} / \mathrm{dl}$ all subjects showed normal cells, justifying the conventional cutoff for defining anaemia. It was thus observed that although the prevalence of anaemia on the basis of $\mathrm{Hb}$ was $77 \cdot 2 \%$, only one-third of them $(27 \cdot 6 \%)$ revealed IDA and a majority of women had nutritional anaemia.

The association of $\mathrm{Hb}$ and IDA with various factors including weight and height of the rural women was examined (Table 3). It was observed that mean $\mathrm{Hb}$ levels for various weight groups varied in a narrow range and $\mathrm{Hb}$ was not near the normal cut-off even for the group with highest weight. This was also true for other maternal factors considered. However, maternal weight showed a positive association with $\mathrm{Hb}$ and a negative association with IDA. Thus, mothers with lower body weight had lower Hb levels $(P=0 \cdot 015)$ and higher prevalence of IDA $(P<0 \cdot 05)$. Mean $\mathrm{Hb}$ levels did not increase significantly with maternal height, but a significant reverse trend was seen in the prevalence of IDA $(P<0 \cdot 05)$. In fact, the highest prevalence of IDA ( $48 \cdot 3 \%)$ was observed among mothers with height less than $145 \mathrm{~cm}$, which is also a cut-off for risk of low birth weight. With regard to BMI, although mean $\mathrm{Hb}$ increased and prevalence of IDA decreased with BMI level, the trends were not statistically significant.

Apart from nutritional status, two demographic factors maternal age and parity - were examined for their association with $\mathrm{Hb}$ level and IDA (Table 3). It was observed that younger mothers $(<20$ years) had higher levels of $\mathrm{Hb}(11 \cdot 2(\mathrm{sD} 1 \cdot 0) \mathrm{g} / \mathrm{dl})$, which decreased significantly $(P=0.002)$ with increasing age. The prevalence of IDA was lower in younger mothers and increased significantly
Table 3 Mean $\mathrm{Hb}$ level and prevalence of iron-deficiency anaemia (IDA) by anthropometric variables, age and parity: rural women of childbearing age (15-35 years), Maharashtra, India

\begin{tabular}{|c|c|c|c|c|c|}
\hline \multirow[b]{2}{*}{ Variable } & \multirow[b]{2}{*}{ Group } & \multirow[b]{2}{*}{$n$} & \multicolumn{2}{|c|}{$\mathrm{Hb}(\mathrm{g} / \mathrm{dl})$} & \multirow[b]{2}{*}{ IDA (\%) } \\
\hline & & & Mean & SD & \\
\hline \multirow[t]{5}{*}{ Weight (kg) } & $<42$ & 122 & $10 \cdot 9$ & $1 \cdot 3$ & $33 \cdot 6$ \\
\hline & $42-47$ & 128 & $11 \cdot 0$ & $1 \cdot 2$ & $27 \cdot 3$ \\
\hline & $47-52$ & 97 & $11 \cdot 2$ & $1 \cdot 2$ & $25 \cdot 8$ \\
\hline & $\geq 52$ & 65 & $11 \cdot \overline{3}$ & $1 \cdot \overline{1}$ & $20 \cdot 0$ \\
\hline & $P$ value & & 0.015 & & 0.05 \\
\hline \multirow[t]{5}{*}{ Height $(\mathrm{cm})$} & $<145$ & 29 & $10 \cdot 6$ & $1 \cdot 6$ & $48 \cdot 3$ \\
\hline & $145-150$ & 78 & $11 \cdot 0$ & $1 \cdot 3$ & $32 \cdot 1$ \\
\hline & $150-155$ & 146 & $11 \cdot 1$ & $1 \cdot 2$ & $22 \cdot 6$ \\
\hline & $\geq 155$ & 159 & $11 \cdot 1$ & $1 \cdot 2$ & $26 \cdot 4$ \\
\hline & $P$ value & & NS & & $<0.05$ \\
\hline \multirow[t]{5}{*}{ BMI $\left(\mathrm{kg} / \mathrm{m}^{2}\right)$} & $<16$ & 25 & $10 \cdot 8$ & $1 \cdot 6$ & $32 \cdot 0$ \\
\hline & $16-18 \cdot 5$ & 129 & $11 \cdot 0$ & $1 \cdot 2$ & $29 \cdot 5$ \\
\hline & $18 \cdot 5-20$ & 108 & $11 \cdot 0$ & $1 \cdot 2$ & $25 \cdot 9$ \\
\hline & $\geq 20$ & 150 & $11 \cdot 1$ & $1 \cdot 2$ & $26 \cdot 7$ \\
\hline & $P$ value & & NS & & NS \\
\hline \multirow[t]{4}{*}{ Age (years) } & $<20$ & 137 & $11 \cdot 2$ & $1 \cdot 0$ & 18.9 \\
\hline & $20-25$ & 184 & $11 \cdot 1$ & $1 \cdot 2$ & $28 \cdot 8$ \\
\hline & $\geq 25$ & 86 & $10 \cdot 6$ & $1 . \overline{5}$ & 38.5 \\
\hline & $P$ value & & 0.002 & & $<0.01$ \\
\hline \multirow[t]{4}{*}{ Parity } & NP with no child & 160 & $11 \cdot 2$ & $1 \cdot 1$ & $22 \cdot 5$ \\
\hline & NP with 1 child & 123 & $11 \cdot 1$ & $1 \cdot 3$ & $24 \cdot 4$ \\
\hline & NP with $\geq 2$ children & 124 & $10 \cdot 8$ & $1 \cdot 2$ & $37 \cdot 9$ \\
\hline & & & 0.04 & & $<0$ \\
\hline
\end{tabular}

NP, non-pregnant.

$P$ value for the significance of linearity trend in mean values (tested using ANOVA) and proportions (tested using the $Z$ test).

$(P=0 \cdot 01)$ with age. Similarly, as parity increased, Hb level decreased significantly $(P=0 \cdot 04)$ and IDA prevalence increased significantly $(P<0 \cdot 01)$. It was highest $(38 \%)$ among women who had parity more than two.

\section{Diet pattern}

The habitual diet pattern was studied using the FFQ. The women's diets were monotonous and lacked variety. Most women were vegetarians and only $10 \%$ could afford to have non-vegetarian food, that too only once per week or once per fortnight. In this population, where access to foods rich in haem Fe foods was limited, pearl millet was the staple food and the major Fe source. Only a few consumed wheat roti. Rice was a costly food item and as such was consumed only during one meal by about $30 \%$ of families. Possible sources of micronutrients were thus 
Table 4 Mean $\mathrm{Hb}$ and prevalence of iron-deficiency anaemia (IDA) by consumption pattern of micronutrient-rich foods: rural women of childbearing age (15-35 years), Maharashtra, India

\begin{tabular}{|c|c|c|c|c|c|c|}
\hline \multirow[b]{2}{*}{ Food group } & \multirow[b]{2}{*}{ Frequency } & \multirow[b]{2}{*}{$n$} & \multirow[b]{2}{*}{$\%$} & \multicolumn{2}{|c|}{$\mathrm{Hb}(\mathrm{g} / \mathrm{dl})$} & \multirow[b]{2}{*}{ IDA $(\%$} \\
\hline & & & & Mean & $\mathrm{SD}$ & \\
\hline \multirow[t]{3}{*}{ Green leafy vegetables } & $<$ Twice weekly & 208 & $52 \cdot 5$ & $11 \cdot 0$ & $1 \cdot 1$ & $30 \cdot 2$ \\
\hline & $\geq$ Twice weekly & 116 & $29 \cdot 3$ & $11 \cdot 1$ & $1 \cdot 2$ & $26 \cdot 8$ \\
\hline & $\geq$ Alternate days & 72 & $18 \cdot 2$ & $11 \cdot 0$ & $1 \cdot 3$ & $28 \cdot 6$ \\
\hline \multirow[t]{3}{*}{ Milk } & None & 256 & $64 \cdot 6$ & $11 \cdot 1$ & $1 \cdot 2$ & $27 \cdot 0$ \\
\hline & $<$ Twice daily & 108 & $27 \cdot 3$ & $11 \cdot 1$ & $1 \cdot 2$ & $28 \cdot 7$ \\
\hline & $\geq$ Twice daily & 32 & $8 \cdot 1$ & $11 \cdot 0$ & $1 \cdot 3$ & $34 \cdot 4$ \\
\hline \multirow[t]{3}{*}{ Fruit } & $<$ Twice weekly & 184 & $46 \cdot 5$ & $11 \cdot 0$ & $1 \cdot 2$ & $29 \cdot 4$ \\
\hline & $\geq$ Twice weekly & 97 & $24 \cdot 5$ & $11 \cdot 0$ & $1 \cdot 2$ & $27 \cdot 8$ \\
\hline & $\geq$ Alternate days & 115 & $29 \cdot 0$ & $11 \cdot 1$ & $1 \cdot 3$ & $26 \cdot 1$ \\
\hline
\end{tabular}

Table 5 Multiple logistic regression analysis for risk of iron-deficiency anaemia among rural women of childbearing age (15-35 years), Maharashtra, India

\begin{tabular}{|c|c|c|c|c|}
\hline Independent variable & Category & OR & $95 \% \mathrm{Cl}$ & $P$ value \\
\hline \multirow[t]{2}{*}{ Pre-pregnancy weight $(\mathrm{kg})$} & $<40$ & $1 \cdot 80$ & $1 \cdot 00,3 \cdot 16$ & 0.05 \\
\hline & $\geq 40$ & $1 \cdot 00$ & ref. & \\
\hline \multirow[t]{2}{*}{ Age at marriage (years) } & $<19$ & 1.93 & $1 \cdot 15,3 \cdot 24$ & 0.013 \\
\hline & $\geq 19$ & $1 \cdot 00$ & ref. & \\
\hline \multirow[t]{2}{*}{ Age at menarche (years) } & $<14$ & $1 \cdot 00$ & ref. & NS \\
\hline & $\geq 14$ & $0 \cdot 76$ & $0 \cdot 44,1 \cdot 32$ & \\
\hline \multirow[t]{2}{*}{ Parity } & $<2$ & $1 \cdot 00$ & ref. & \\
\hline & $\geq 2$ & $2 \cdot 23$ & $1 \cdot 25,3 \cdot 96$ & 0.007 \\
\hline \multirow{2}{*}{ Education } & $<10$ th standard & $1 \cdot 17$ & $0.56,2 \cdot 44$ & \\
\hline & $\geq 10$ th standard & $1 \cdot 00$ & ref. & \\
\hline \multirow{2}{*}{ GLV consumption } & $<$ Alternate days & 0.67 & $0.33,1.34$ & NS \\
\hline & $\geq$ Alternate days & $1 \cdot 00$ & ref. & \\
\hline \multirow[t]{2}{*}{ Milk consumption } & No & $1 \cdot 30$ & $0 \cdot 79,2 \cdot 14$ & NS \\
\hline & Yes & $1 \cdot 00$ & ref. & \\
\hline \multirow[t]{2}{*}{ Fruit consumption } & $<$ Alternate days & $0 \cdot 87$ & $0.51,1.51$ & NS \\
\hline & $\geq$ Alternate days & $1 \cdot 00$ & ref. & \\
\hline
\end{tabular}

GLV, green leafy vegetables; ref., reference category.

from foods such as GLV, milk and seasonal fruits. Analysis of the consumption frequency of these micronutrient-rich foods (Table 4) showed that $53 \%$ of women consumed GLV less than twice weekly in spite of the fact that they are not costly foods, while milk - being a costly food item - was not consumed by $65 \%$ of the women. Even among women who reported milk consumption, it was very low, often only in tea. Similarly, consumption of seasonal fruits too was low with $47 \%$ of women consuming them less than twice weekly. The frequency of consumption of these foods did not, however, show a strong association with $\mathrm{Hb}$ levels or IDA prevalence.

Multiple logistic regression analysis was performed (Table 5) to estimate the odds ratio and 95\% confidence interval for risk of IDA for the various factors examined above. It can be seen that, controlling for all confounders, the factors that showed significant odds ratio for IDA risk were higher maternal parity $(\geq 2)$, younger age at marriage $(<19$ years) and poor pre-pregnancy weight $(<40 \mathrm{~kg})$. Replacing maternal height in place of weight in this model, it was observed that poor maternal height $(<145 \mathrm{~cm})$ was also associated with significant risk $(\mathrm{OR}=2 \cdot 48,95 \%$ CI $1 \cdot 07,5 \cdot 74)$ for IDA.
The reasons for poor consumption of GLV were investigated from the analysis of qualitative information collected (Table 6). The majority of families had small landholdings which were mostly non-irrigated and pearl millet was the major crop cultivated. Besides pearl millet, groundnut, pulses and GLV were cultivated. Although $63 \%$ of the women reported that GLV were cultivated for home consumption as well as for selling purposes, the preference was for the latter. GLV consumption was affected by seasonality and was high in the rainy season but very low in summer. Only $52 \%$ of the women said that they grow some vegetables around the house and it was often some creepers. The purchase of vegetables from the market was rarely done by the young mothers (17\%) and instead was done by either the husband or the in-laws. GLV were often (94\%) prepared in the form of gravy, by removing the excess water during the cooking process. Some $78 \%$ of the women reported they like GLV but mentioned several reasons for low consumption, such as: (i) they do not know different recipes that can be prepared from GLV; (ii) their family does not cultivate GLV and does not buy them; (iii) their husband and children do not like GLV; (iv) GLV perish quickly (most families do not 
Table 6 Qualitative information related to consumption of green leafy vegetables (GLV) among rural women of childbearing age (15-35 years), Maharashtra, India ( $n$ 400)

\begin{tabular}{|c|c|c|}
\hline Variable & Details & Frequency (\%) \\
\hline \multirow[t]{2}{*}{ Owns a farm } & Yes & $86 \cdot 3$ \\
\hline & Non-irrigated & $74 \cdot 4$ \\
\hline \multirow[t]{3}{*}{ Crops grown } & Groundnut & $83 \cdot 9$ \\
\hline & Pulses & $64 \cdot 0$ \\
\hline & GLV & $60 \cdot 2$ \\
\hline \multirow[t]{3}{*}{ GLV grown for } & Home use & $10 \cdot 2$ \\
\hline & Selling & $26 \cdot 5$ \\
\hline & Both & $62 \cdot 7$ \\
\hline \multirow[t]{4}{*}{ Consumption of GLV in season } & Rainy & $84 \cdot 5$ \\
\hline & Winter & $77 \cdot 5$ \\
\hline & Summer & $42 \cdot 4$ \\
\hline & Throughout the year & $57 \cdot 0$ \\
\hline \multirow[t]{2}{*}{ Currently growing vegetables around the house } & Yes & $51 \cdot 8$ \\
\hline & No & $48 \cdot 2$ \\
\hline \multirow[t]{3}{*}{ Purchasing of vegetables from the market is done by } & Woman & $17 \cdot 4$ \\
\hline & Husband & $37 \cdot 1$ \\
\hline & Others & $45 \cdot 5$ \\
\hline \multirow[t]{3}{*}{ Decision of what to cook } & Woman & $72 \cdot 4$ \\
\hline & Mother-in-law & $23 \cdot 5$ \\
\hline & Others & $4 \cdot 0$ \\
\hline \multirow[t]{2}{*}{ Liking for GLV } & Like & $77 \cdot 5$ \\
\hline & Dislike & $22 \cdot 5$ \\
\hline \multirow[t]{2}{*}{ Method of GLV preparation } & Dry & $5 \cdot 0$ \\
\hline & Gravy but removing excess water & $93 \cdot 7$ \\
\hline \multirow[t]{3}{*}{ Reasons for frequent use of GLV } & Grown on farm & $54 \cdot 1$ \\
\hline & Like it & $42 \cdot 3$ \\
\hline & Others & $3 \cdot 6$ \\
\hline \multirow[t]{4}{*}{ Reasons for not consuming GLVs frequently } & Don't grow & $45 \cdot 8$ \\
\hline & Don't like & $14 \cdot 8$ \\
\hline & Shrinks after cooking & $21 \cdot 1$ \\
\hline & Others (perishes quickly; husband and children do not like) & $18 \cdot 3$ \\
\hline
\end{tabular}

have a refrigerator); and (v) cooked quantity of a GLV recipe is often not adequate for the entire family.

\section{Discussion}

Anaemia remains endemic in women of childbearing age in rural India despite intervention measures such as the distribution of Fe-folic acid tablets to each pregnant woman. The failure to obtain the desired effect of the intervention is often attributed to logistical reasons ${ }^{(4,22)}$ and low compliance, especially due to the side-effects associated with Fe supplementation. There is hardly any interaction between health provider and health beneficiary in India, and this could be responsible for the poor compliance. Alternatively, it may be necessary to examine reasons for low maternal intakes, especially $\mathrm{Fe}$ intakes that are responsible for the high anaemia prevalence. Since many health problems in rural India have roots in socio-cultural conditions, the present study examined some of the social conditions in three Indian villages to help to explain the endemic nature of IDA in rural women of childbearing age. Our study thus reports that, apart from long-term undernutrition, anaemia was associated with sociodemographic factors which were consistent with poor intake of Fe-rich foods like GLV.

The prevalence of anaemia in young rural mothers observed in our study was as large as $77 \%$ and confirms the anaemia prevalence reported by other studies from different states in India ${ }^{(23,24)}$. Hookworm infection and malaria are endemic in this population and region, and the majority of the population may in fact have worm infestation. Despite this we found that the prevalence of IDA was only $27 \%$, which indicates that other causes of anaemia may be prevalent in this population. A similar observation was reported in the case of Nepali women ${ }^{(25)}$. Although ferritin is commonly considered for detecting $\mathrm{Fe}$ deficiency, it is reported ${ }^{(26)}$ that there may be normal serum ferritin values despite a true Fe deficiency. In contrast, RBC morphology clearly revealed that Fe deficiency is largely confined to $\mathrm{Hb}$ level below $11 \mathrm{~g} / \mathrm{dl}$, as $75 \%$ of women with $\mathrm{Hb}$ below this level had IDA. Thus RBC morphology is not only a simple tool for identifying IDA but is cost-effective too, compared with other biochemical indicators.

The association of IDA with nutritional status has been reported by only few researchers. We observed that lower $\mathrm{Hb}$ levels and higher prevalence of IDA were associated with lower maternal body weight and height, indicating that long-term undernutrition present in young rural women is one of the factors responsible for anaemia. Very thin and very poor women in urban areas of India have also been shown to have highest risk of anaemia ${ }^{(27)}$. The fact that the health status of women in India reflects gender discrimination from birth, inadequate distribution of health resources, early and frequent reproductive 
cycling and reproductive tract infections ${ }^{(28)}$ may partly contribute to the high prevalence of anaemia in women from low and poor sections of the population in India.

We observed that anaemia prevalence was higher among elderly and multiparous mothers. Additionally, multiple logistic regression showed that younger age at marriage $(<19$ years) also increased risk for IDA. Almost $41 \%$ of the women in our study got married before 18 years of age, i.e. the legal age of marriage in India. Poor nutrition as revealed by stunting and higher age at menarche, early age of marriage and repeated pregnancies in these young rural mothers was probably responsible for their poor obstetric history ${ }^{(29)}$ and depleted Fe stores ${ }^{(30)}$.

Nutrient intakes of the women were 7950 (sD 1975) kJ/d (1900 (sD 472) kcal/d) for energy, 49.9 (SD 13.2 g)/d for protein and $22.0(\mathrm{sD} 6.9 \mathrm{mg}) / \mathrm{d}$ for $\mathrm{Fe}$ and were low, especially for $\mathrm{Fe}(69 \%)$, compared with the recommended dietary allowances ${ }^{(31)}$. As the participants in the study were from a subsistence farming community, poverty was indeed one of the reasons for overall lower food intakes. The consumption of micronutrient-rich foods such as GLV, fruits and milk assessed from the FFQ was also low. We are aware that in vegetarian diets Fe bioavailability is affected due to inhibitors like phytates or enhancers like vitamin C. However, it was not possible to estimate these factors using the FFQ. Moreover, consumption of GLV was not associated with $\mathrm{Hb}$ level or prevalence of IDA probably due to the short recall period. Lack of significant changes in Fe intake even after supplementation of Fe for 9 months was attributed to inaccuracies and insufficient power to detect changes in dietary data ${ }^{(32)}$.

Although lower intakes of micronutrient-rich foods like GLV, fruits and milk have been reported ${ }^{(19)}$ in mothers from India, the social aspects associated with it have received little attention. Overall food intake could be affected because of unaffordability; while this may be true in the case of milk and fruits, it is unlikely to be so for GLV which are cheaper. The qualitative data in our study revealed that lower consumption of GLV was due not only to poor landholdings or seasonality but also to the preference for selling GLV in the market rather than home consumption. Second, although GLV were available at the marketplace and most women liked GLV preparations, one of the reasons for not buying the GLV was that they are perishable and that husbands and children did not like them. In this community, like or dislike of GLV was certainly not indicative of shifts in social status; it just means that the taste of recipes made from GLV was not preferred. Moreover, women working on farms are paid their wages in cash and not in kind. Third, the social aspect was that the purchase of vegetables from the market was in the domain of duties of male members or the in-laws in the family and not the young women. Thus, our findings highlight that the low consumption of GLV, which are treasures of micronutrients including $\mathrm{Fe}$, is associated with genuine social reasons that are hardly looked into.
Finally, our informal meetings were valuable in bringing to the women's attention important aspects related to nutrition and health education. A large number of women did not know simple symptoms of anaemia or its adverse effects on mother and child; many did not know about the benefits of Fe-folic acid tablets, nor were they aware of the fact that GLV are rich sources of not only Fe but several micronutrients which can help in preventing anaemia and improving fetal growth. However, the majority of women in our study were willing to learn new recipes for GLV as cooking is dear to Indian women. A study ${ }^{(33)}$ from Gaziabad, Uttar Pradesh, showed that counselling, motivation and periodic reinforcement to take the Fe supplementation daily and regularly resulted in improved compliance; and this, combined with improvements in dietary intake, especially GLV consumption, resulted in improved mean $\mathrm{Hb}$ level in an intervention group compared with a control group. However, although there is much evidence supporting the use of Fe supplementation in vulnerable groups, findings on the effects of nutrition education without supplementation and/or food fortification are lacking ${ }^{(34)}$.

In conclusion, our observations indicate that the massive problem of anaemia in rural India is associated with sociodemographic factors and reveal a great potential for social actions. As ignorance is one of the root causes of disease in rural areas, education to change knowledge, attitudes and household dietary practices may be required to effect positive changes in consumption patterns and nutritional status. It is believed that lack of knowledge of the causes and consequences of nutritional deficiencies may influence food choices even in resource-poor populations ${ }^{(35)}$. Simple approaches such as incorporating a component of health education in the existing anaemia control programme to increase its efficacy would be beneficial. Second, efforts to generate nutritional awareness through kitchen garden activities, or demonstrating Fe-rich recipes from GLV, arranging food exhibitions, etc., may be helpful for improving intakes of micronutrientrich foods. In Indonesia social marketing played a critical role in increasing the consumption of vitamin A from plant and animal sources ${ }^{(36)}$. It is beyond doubt that not only operational research on how best to improve the existing Fe supplementation programme is needed ${ }^{(26)}$, but also new and innovative strategies are required to improve the overall health and nutritional status of adolescent girls before they enter their reproductive years.

\section{Acknowledgements}

Sources of funding: The study was supported by the Department of Science and Technology, New Delhi. Conflict of interest declaration: No are conflicts of interest. Authors' contributions: S.R. was the Principal Investigator and was responsible for planning of the study, interpreting 
the results and writing the manuscript. S.J. was responsible for execution and supervision of the data collection and also statistical analysis of the data. A.K. participated in statistical analysis of the data. P.B. and B.P. participated actively in data collection. Acknowledgements: The authors wish to thank the Science and Society Division, Department of Science and Technology, New Delhi, for providing funds for carrying out the research. They also thank all the rural mothers who participated in the study.

\section{References}

1. United Nations Administrative Committee on Coordination, Sub-committee on Nutrition (1991) Controlling Iron Deficiency. ACC/SCN State of the Art Series, Nutrition Policy Discussion Paper no. 9. Geneva: ACC/SCN.

2. Seshadri S, Sharma K, Ra AE et al. (1994) Iron supplementation to control pregnancy anaemia. Proc Nutr Soc India 41, 131-140.

3. Sood SK, Ramachandran K, Mathur M et al. (1975) WHO sponsored collaborative studies on nutritional anaemia in India. 1. The effects of supplemental oral iron administration to pregnant women. QJ Med 44, 241-258.

4. ICMR Task Force Study (1989) Evaluation of the National Nutritional Anaemia Prophbylaxis Programme. New Delhi: Indian Council of Medical Research.

5. ICMR Task Force Study (1992) Field Supplementation Trials in Pregnant Women with $60 \mathrm{mg}, 120 \mathrm{mg}$ and $180 \mathrm{mg}$ of Iron with $500 \mathrm{mcg}$ of Folic Acid. New Delhi: Indian Council of Medical Research.

6. Christian P, Abbi R, Gujral S et al. (1989) At risk status of pregnant women of Panchmahals (Gujarat) and Ghandrapur (Maharashtra). Arogya J Health Sci 15, 85-91.

7. Agarwal DK, Agarwal KN \& Tripathi AM (1987) Nutritional status in rural pregnant women of Bihar and Uttar Pradesh. Indian Pediatr 24, 119-125.

8. Sarin AR (1995) Severe anaemia of pregnancy: recent experience. J Gynaecol Obstet 50, Suppl. 27, 545-549.

9. Ramachandran P (1989) Nutrition in pregnancy. In Women and Nutrition in India, pp. 153-193 [C Gopalan and S Kaur, editors]. New Delhi: Nutrition Foundation of India Special Publication Services.

10. Ratnam SG, Rao KB \& Arul Kumaran S (1992) Obstetrics and Gynaecology for Postgraduates, vol. 1. Madras: Orient Longman.

11. Bothwell TH (2000) Iron requirements in pregnancies and strategies to meet them. Am J Clin Nutr 72, 1 Suppl., 257S-264S.

12. Rao BSN (1978) Studies on iron deficiency anaemia. Indian J Med Res Suppl. 68, 58.

13. Toteja GS \& Singh P (2004) Micronutrient Profile of the Indian Population. New Delhi: Indian Council of Medical Research.

14. Vijayalaxmi P, Kuputhai U \& Meenakshi Devi N (1988) Nutritional profile of selected expectant mothers and the cost of pregnancy. Indian J Nutr Diet 25, 247-253.

15. Ratwani L \& Varma M (1989) A study of nutritional status and food practices of the pregnant and lactating women residing in selected desert areas of Jodhpur. Indian J Nutr Diet 26, 304-310.
16. Piers LS, Diggavi S, Thangam S et al. (1995) Changes in energy expenditure, anthropometry and energy intake during the course of pregnancy and lactation in well nourished Indian women. Am J Clin Nutr 61, 501-513.

17. Hutter I (1996) Reduction of food intake during pregnancy in rural South India. Trop Med Int Health 1, 399-405.

18. Gupta R \& Sharma I (1980) An overview of the dietary consumption pattern of pregnant and lactating mothers of Haryana region, Hissar. Indian J Nutr Diet 17, 13-19.

19. Rao S, Yajnik CS, Kanade A et al. (2001) Intake of micronutrient rich foods in rural Indian mothers is associated with the size of their babies at birth: Pune Maternal Nutrition Study. J Nutr 131, 1217-1224.

20. Dacie JV \& Lewis SM (2006) Practical Haematology, 10th ed. Edinburgh: Churchill Livingstone.

21. Snedecor GW \& Cochran WG (1967) Statistical Methods, 6th ed. New Delhi: Oxford \& IBH Publishing Co.

22. Stoltzfus RJ (2001) Defining iron-deficiency anaemia in public health terms: a time for reflection. $J$ Nutr 131, 2 Suppl. 2, 565S-567S.

23. Saibaba A, Mohan Ram M, Ramana Rao GV et al. (2002) Nutritional status of adolescent girls of urban slums and the impact of IEC on their nutritional knowledge and practices. Indian J Community Med 27, 151-156.

24. Kaur S, Deshmukh PR \& Garg BS (2006) Epidemiological correlates of nutritional anaemia in adolescent girls of rural Wardha. Indian J Community Med 31, 255-258.

25. Chandyo RK, Strand TA, Ulvik RJ et al. (2007) Prevalence of iron deficiency and anemia among healthy women of reproductive age in Bhaktapur, Nepal. Eur J Clin Nutr 61, 262-269.

26. Beard JL (2000) Effectiveness and strategies of iron supplementation during pregnancy. Am J Clin Nutr 71, 5 Suppl., 1288S-1294S.

27. Bentley ME \& Griffiths PL (2003) The burden of anemia among women in India. Eur J Clin Nutr 57, 52-60.

28. Bhatia JC \& Cleland J (1995) Self reported symptoms of gynecological morbidity and their treatment in South India. Stud Fam Plann 26, 203-216.

29. Rao S, Gokhale M, Joshi S et al. (2010) Early life undernutrition and adolescent pregnancy outcome in India. Ann Hum Biol 37, 475-487.

30. Lenders CM, McElarth TF \& Scholl TO (2000) Nutrition and adolescent pregnancy. Curr Opin Pediatr 12, 291-296.

31. Indian Council of Medical Research (1998) Nutrient Requirements and Recommended Dietary Allowances for Indians. New Delhi: ICMR.

32. Patterson AJ, Brown WJ, David CK et al. (2001) Dietary treatment of iron deficiency in women of childbearing age. Am J Clin Nutr 74, 650-656.

33. Garg A \& Kashyap S (2006) Effect of counseling on nutritional status during pregnancy. Indian J Pediatr $\mathbf{7 3}$, 687-692.

34. Amani R \& Soflaei M (2006) Nutrition education alone improves dietary practices but not hematologic indices of adolescent girls in Iran. Food Nutr Bull 27, 260-264.

35. Jones KM, Specio SE, Shrestha P et al. (2005) Nutrition knowledge and practices and consumption of vitamin A rich plants by rural Nepali participants and non participants in a kitchen garden program. Food Nutr Bull 26, 198-208.

36. de Pee S, Bloem MW, Satoto et al. (1998) Impact of a social marketing campaign promoting dark green leafy vegetables and eggs in central Java, Indonesia. Int J Vitam Nutr Res 68, 389-398. 